\title{
Uncertainty in living-donor transplant settings: a review of the literature
}

\begin{abstract}
Purpose: To organize the knowledge regarding uncertainty among recipients, donors, and family members in living-donor transplant cases, and identify potential consequences of uncertainty.
\end{abstract}

Method: The keywords "living donor*" and "uncertainty" were used to search PubMed and CINAHL databases for studies published between 2000 and August 2016. By using Mishel's uncertainty in illness theory 1 as a reference, contents related to uncertainty were extracted from the articles.

Result: Twelve studies were selected. None defined uncertainty clearly. Studies discussing living-donor kidney transplant recipients or donors were the most common. Time prior to a transplant, potentially being a recipient or donor, and being on the transplant waiting list were frequently reported as stages in which recipients and donors perceived uncertainty. Poor psychosocial outcomes, including confusion, anxiety, and needing help from healthcare providers, were reported as the most frequent consequences of uncertainty. On the other hand, becoming a risk taker was also reported as a consequence of uncertainty among donors.

Conclusion: No studies consider uncertainty as a strength or an opportunity for the growth of recipients and donors. Future research should identify interventions to facilitate personal growth through managing uncertainty.
Volume 4 Issue I - 2017

Katsuhiro Hiratsuka

Department of Nursing, Sophia University, Japan

Correspondence: Katsuhiro Hiratsuka, Faculty of Human Science, Department of Nursing, Sophia University, Japan, Tel +81339506903, Email k-hiratsuka@sophia.ac.jp

Received: September 27, 2017| Published: October 18, 2017

Keywords: uncertainty, living-donor transplant, recipient, donor, mishel's uncertainty in illness theory, review

\section{Introduction}

Uncertainty in relation to illness has been defined as the inability to determine the meaning of illness-related events, and managing uncertainty may result in personal growth. ${ }^{1,2}$ Transplant therapy has become an increasingly common treatment; however, uncertainty still exists among recipients and their families. Due to the higher proportion of living-donor transplants between relatives in Japan, managing uncertainty is not only necessary for recipients, but also for donors and family members. However, uncertainty and its management have been understudied in this population. Thus, this review aimed to organize the knowledge regarding uncertainty among recipients, donors, and family members in living-donor transplant cases, and identify potential consequences of uncertainty.

\section{Methods}

A flow diagram of the selection of studies and inclusion/exclusion process is shown in Figure 1. The keywords "living donor*" and "uncertainty" were used to search PubMed and CINAHL databases. A search was performed to identify studies published between 2000 and August 2016. As selection criteria, studies had to refer to cognitive uncertainty of recipients, donors, and family members in living-donor transplant cases and be original articles written in English. By using Mishel's uncertainty in illness theory 1 as a reference, contents related to uncertainty were extracted from the articles. The studies that did not sample living-donor transplant recipients or donors, and did not refer to uncertainty as a cognitive status, were excluded from the analysis.

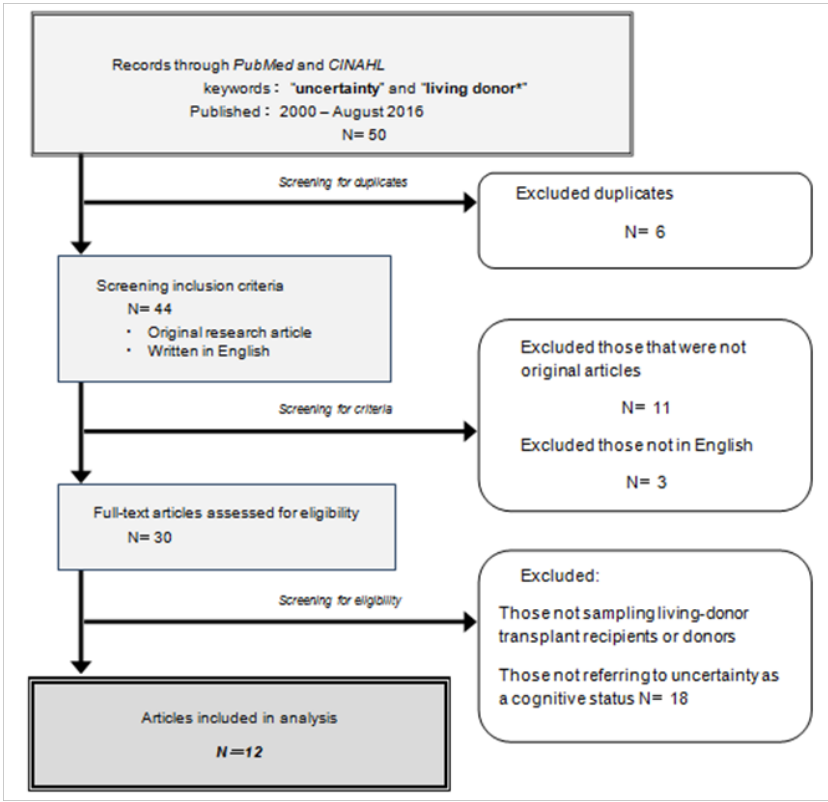

Figure I Flow diagram of study selection and inclusion/exclusion process.

\section{Results}

Twelve studies were selected in this review Table 1. Studies on living-donor kidney transplant recipients or donors were the most 
common. ${ }^{3-10}$ but studies on stem cell transplant ${ }^{11,12}$ liver transplant ${ }^{8,13}$ and lung transplant14 were also included. No studies focused on uncertainty of family members. Time prior to a transplant, potentially being a recipient or donor, and being on the transplant waiting list were frequently reported as stages in which recipients and donors perceived uncertainty. The stimuli frames of uncertainty included "knowledge deficits about living-donor transplant", " "recipients' health appearing to be stable", ${ }^{6}$ and "constant threat of rejection or infection". ${ }^{14}$

Table I List of studies included in the analysis

\section{Literature}

I. Durst CL, Horn MV, MacLaughlin EF, et al. Psychosocial responses of adolescent cystic fibrosis patients to lung transplantation. Pediatric Transplantation. 200 I;5(I):27-3I.

2. Neuhaus TJ,Wartmann M,Weber M, et al. Psychosocial impact of living-related kidney transplantation on donors and partners. Pediatric Nephrology. 2005;20(2):205-209.

3. Williams AM, Broderick D, O'Driscoll C, et al. Development of a donor driven assessment protocol in Western Australia based on experiences of living renal donors. Journal Of The American Nephrology Nurses' Association. 2007;34(I):66-70.

4. Young A, Karpinski M,Treleaven D, et al. Differences in tolerance for health risk to the living donor among potential donors, recipients, and transplant professionals. Kidney International. 2008;73(I0): I I59-I I 66.

5. Wanner M, Bochert S, Schreyer IM, et al. Losing the genetic twin: donor grief after unsuccessful unrelated stem cell transplantation. BMC Health Services Research. 2009;9:2.

6. Boulware LE, Hill-Briggs F, Kraus ES, et al. Identifying and addressing barriers to African American and non-African American families' discussions about preemptive living related kidney transplantation. Progress In Transplantation. 20 I I;2 I (2):97-I04.

7. Ismail SY, Massey EK, Luchtenburg AE, et al. Religious attitudes towards living kidney donation among Dutch renal patients. Medicine, Health Care, and Philosophy. 20I2;15(2):22I-227.

8. Pillay B, Lee SJ, Katona L, et al.The psychosocial impact of haematopoietic SCT on sibling donors. Bone Marrow Transplantation. 20I2;47(I0):|36|-|365.

9. Dew MA, DiMartini AF, DeVito Dabbs AJ, et al. Preventive intervention for living donor psychosocial outcomes: feasibility and efficacy in a randomized controlled trial.American Journal of Transplantation. 20I3;।3(I0):2672-2684.

10. Molinari M, Jacob Matz, Sarah DeCoutere, et al. Live liver donors' risk thresholds: risking a life to save a life. HPB:The official journal of the international hepato pancreato biliary association. 20I4;I6(6):560-574.

II. Gordon EJ, Mullee JO, Ramirez DI, et al. Hispanic/Latino concerns about living kidney donation: a focus group study. Progress in Transplantation. 20I4;24(2):I52-16.

12. Ganji S, Patti L. Ephraim, Jessica M,Ameling, et al. Concerns regarding the financial aspects of kidney transplantation: perspectives of pre-transplant patients and their family members. Clinical Transplantation. 20 I4;28(I0): I I I I-I I 30.

There were no studies clearly defining uncertainty. Typically, uncertainty was related to "information on donating", "Health outcomes for the recipient and donor". ${ }^{12}$ "Future or long-term risk", "Duration for which insurance plans paid for medications,", ${ }^{10}$ and "When to initiate discussions about the transplant". ${ }^{\text {Poor }}$ psychosocial outcomes, including confusion, anxiety, and needing help from healthcare providers, were reported as the most frequent consequences of uncertainty for recipients or donors. ${ }^{6-8,12}$ On the other hand, becoming a risk taker (i.e., accepting a certain level of donor risk and agreeing that living donation was acceptable) was also reported as a consequence for potential donors when the long-term health effects of donating were more uncertain. ${ }^{13}$

\section{Discussion and conclusion}

Few studies have focused on uncertainty in living-donor transplant cases. Uncertainty was reported more often pre-transplant than posttransplant. This is consistent with previous research on uncertainty in brain-death liver transplant recipients. ${ }^{15}$ Additionally, knowledge related to donors' uncertainty may be expanded by this review. No studies considered uncertainty as strength or an opportunity for the growth of recipients and donors. However, uncertainty might motivate potential donors' decision for living-donor transplant. Future research should identify interventions to facilitate personal growth managing uncertainty.

\section{Acknowledgements}

This work was supported by JSPS KAKENHI Grant Number JP17H07104. A part of this study was presented at the 20th East Asian Forum of Nursing Scholars.

\section{Conflict of interest}

The author has no financial conflict of interest to disclose concerning this study.

\section{References}

1. Mishel MH. Uncertainty in Illness. The Journal of Nursing Scholarship.1998;20(4):225-232.

2. Mishel MH. Reconceptualization of the uncertainty in illness theory. $J$ Nurs Sch. 1990;22(4):256-262.

3. Neuhaus TJ, Wartmann M, Weber M, et al. Psychosocial impact of living-related kidney transplantation on donors and partners. Pediatr Nephrol. 2005;20(2):205-209.

4. Williams AM, Broderick D, O'Driscoll C, et al. Development of a donor driven assessment protocol in Western Australia based on experiences of living renal donors. Nephrol Nurs J. 2007;34(1):66-70.

5. Young A, Karpinski M, Treleaven D, et al. Differences in tolerance for health risk to the living donor among potential donors, recipients, and transplant professionals. Kidney Int. 2008;73(10):1159-1166. 
6. Boulware LE, Hill Briggs F, Kraus ES, et al. Identifying and addressing barriers to African American and non-African American families discussions about preemptive living related kidney transplantation. Prog Transplant. 2011;21(2):97-104.

7. Ismail SY, Massey EK, Luchtenburg AE, et al. Religious attitudes towards living kidney donation among Dutch renal patients. Med Health Care Philos. 2012;15(2):221-227.

8. Dew MA, DiMartini AF, DeVito Dabbs AJ, et al. Preventive intervention for living donor psychosocial outcomes: feasibility and efficacy in a randomized controlled trial. Am J Transplant. 2013;13(10):2672-2684.

9. Gordon EJ, Mullee JO, Ramirez DI, et al. Hispanic/Latino concerns about living kidney donation: a focus group study. Prog Transplant. 2014;24(2):152-162.

10. Ganji S, Ephraim PL, Ameling JM, et al. Concerns regarding the financia aspects of kidney transplantation: perspectives of pre-transplant patients and their family members. Clin Transplant. 2014;28(10):1121-1130.
11. Wanner M, Bochert S, Schreyer IM, et al. Losing the genetic twin: donor grief after unsuccessful unrelated stem cell transplantation. BMC Health Serv Res. 2009;9:2.

12. Pillay B, Lee SJ, Katona L, et al. The psychosocial impact of haematopoietic SCT on sibling donors. Bone Marrow Transplant. 2012;47(10):1361-1365.

13. Molinari M, Matz J, DeCoutere S, et al. Live liver donors' risk thresholds: risking a life to save a life. $H P B($ Oxford). 2014;16(6):560-574.

14. Durst CL, Horn MV, MacLaughlin EF, et al. Psychosocial responses of adolescent cystic fibrosis patients to lung transplantation. Pediatr Transplant. 2001;5(1):27-31.

15. Lasker JN, Sogolow ED, Olenik JM, et al. Uncertainty and liver transplantation: women with primary biliary cirrhosis before and after transplant. Women \& Health. 2010;50(4):359-375. 